into food values, who would have us believe that "Correct nutrition cannot be left to instinct, or to the use of natural unspoilt foods, or to a varied diet", and he adduces as evidence to support his condemnation, a personal experience above criticism: "I have raised a family of seven. . . . Archbishops and Royalty are showing interest in clearing slums. The Bishops need to take their crooks in hand and first lead their flocks to proper food".

\section{Value of the Motion Camera for Testing Purposes}

THE cinema camera and similar recording cameras are now usefully employed in connexion with the testing of moving apparatus. In a paper by W. Wilson on the testing of electrical equipment read to Section G (Engineering) of the British Association and published in full in Engineering for October 6, many illustrations are shown proving practical utility. In tests of electrical circuit-breakers, fuses, lightning arresters, etc., the significant part of the test lasts only 20-140 milli-seconds. A complete record can therefore be supplied by only a few feet of the film. An example is shown of twelve pictures taken from a short circuit to earth at a 'Grid' substation. The arc was struck between a pair of 'horns' of an arrester by bridging them with a fuse wire prior to the closing of the main switch. The successive shapes assumed by the are as it rapidly extends are shown, as well as the relative intensity of the various stages of the phenomenon and their duration. A blizzard was blowing when the photograph was taken but the arc attained a length of about twenty feet. Experiments with exactly similar fuse wires show that when they 'blow' with direct current, the arc lasts a third of a second, but with alternating current it is over in one sixteenth of a second. The common theory that an are snaps at one point like a stretched thread is erroneous. The photographs show that the arc persists until there is not sufficient electrical output to maintain its temperature and consequent ionisation. It then fades away uniformly over its whole length. The motion camera method was usefully employed in testing the 19,000-ton electrically propelled liner Queen of Bermuda. By photographing an assembly of 17 different instruments, most useful results were obtained as the ship was put through a specified series of manceuvres.

\section{Electrification of the Polish Railways}

WE learn from the English Electric Journal for September that Poland has decided to electrify the main Warsaw junction railways. For this purpose a contract involving the sum of two million pounds has been signed with the English Electric Co. Warsaw is the largest city in Poland and has a population of $1,100,000$. For some time the present layout of the railway tracks has caused great inconvenience arising from the loss of time in moving trains from one side of the city to the other owing to the congestion of the traffic. At present there are four principal stations in Warsaw connecting the city with Vienna, Danzig, Moscow, etc. These stations are all connected by a loop line and the increased traffic has slowed down train movements. The
Government has decided that the best solution is to construct a new line across the city, part of which will be through a tunnel and part over a bridge and viaduct. This permits the closing of two stations, and all passenger traffic will be concentrated at the new central station. Over the Vistula, a new bridge, which is about $\mathbf{5 5 0}$ yards in length, has just been completed. In order to operate trains through the tunnel, which is nearly completed, it has been decided to electrify three of the most important lines radiating from Warsaw. For the local passenger services motor-coaches will be used, but electric locomotives will be used to haul international and through expresses on the new junction line. The commission appointed by the Government recommended the use of direct current at 3,000 volts. Each motor-coach will be equipped with four 200 horse power 1,500 volt motors, two motors being connected in permanent series to operate off the 3,000 volt trolley system.

\section{History and Uses of Maps}

Dr. F. J. NoRTH has written a useful little pamphlet on this subject (Maps : their History and Uses, with Special Reference to Wales. (A Handbook to a Temporary Exhibition, July to October 1933.) By Dr. F. J. North. Pp. 45. (Cardiff : National Museum of Wales, 1933.) 6d.) It is primarily intended as a handbook to a temporary exhibition of maps held in the Museum during the past summer, but it has a wider value in being a summary of the development of maps with more special reference to Wales and to Great Britain in general. A final section of the pamphlet gives a sketch of the development of the geological map. Though the work, in view of its object, is written in a popular style, it contains much of interest concerning early maps and the history of early cartographers and some account of their methods. There is also some discussion of methods of cartography and there are references to larger works.

\section{British Association Seismological Committee}

THE report of the Committee for the year 1932-33 contains a notice of the death of a valued member, Dr. J. E. Crombie, who has left a legacy of $£ 1,000$ after the death of his wife for the work of the Committee. It also refers to work by several members of the Committee, on recent Scottish earthquakes, on high-focus earthquakes and microseisms, and Messrs. Jeffreys and Bullen's revision of the standard seismological tables. Interesting memorials of the earliest earthquake station in England have recently been obtained by the Science Museum, South Kensington; Miss Morey, of Newport, I. of W., presented the original lamp-post on which Milne erected his first seismograph at Shide. The drum and recording mechanism have been purchased by the Museum, and an effort will be made to reconstruct the instrument as accurately as possible.

\section{International Union of Geodesy and Geophysics}

THE Fifth Assembly of the International Union of Geodesy and Geophysics was held at Lisbon on 